Research Article

\title{
Evaluation of antidiabetic activity of Oxalis corniculata in streptozotocin induced diabetic rats
}

\author{
Arijit Dutta*, Mangala Lahkar, Chimi Handique
}

Department of Pharmacology, Gauhati Medical College, Guwahati, Assam, India

Received: 22 July 2016

Accepted: 28 August 2016

\section{*Correspondence to:}

Dr. Arijit Dutta,

Email: drarijit85@gmail.com

Copyright: (C) the author(s), publisher and licensee Medip Academy. This is an openaccess article distributed under the terms of the Creative Commons Attribution NonCommercial License, which permits unrestricted noncommercial use, distribution, and reproduction in any medium, provided the original work is properly cited.

\begin{abstract}
Background: Oxalis corniculata is traditionally well known for its versatile uses. The present study was carried out to evaluate the antidiabetic action of ethanolic extract of Oxalis corniculata in streptozotocin induced diabetic albino rats.

Methods: To look for the antidiabetic effect the albino rats were divided into 5 groups, each consisting of 6 animals. Diabetes was induced by a single i.p. injection of streptozotocin at a dose of $50 \mathrm{mg} / \mathrm{kg}$ body weight. Standard drug, glibenclamide and ethanolic extract of Oxalis corniculata (EEOC) at doses $200 \mathrm{mg} / \mathrm{kg}$ and $400 \mathrm{mg} / \mathrm{kg}$ body weight was fed to the rats and it was continued till the end of the study. The blood glucose levels were estimated on day $0,3,7$, 14 and 21 day. The standard drug and the extract were fed from day 4 onwards.

Results: The antidiabetic property of the extract has shown increasing trend with increase in dose and there was a gradual decrease in blood glucose levels with increased period of exposure to the test drug.
\end{abstract}

Conclusions: Results obtained in this study substantiate the anti-diabetic activity of EEOC leaves.

Keywords: Antidiabetic, Oxalis corniculata, Streptozotocin

\section{INTRODUCTION}

Diabetes is one of the major chronic non-communicable metabolic diseases characterized by hyperglycemia resulting from defects in insulin secretion, insulin action or both. The chronic hyperglycemia of diabetes is associated with long-term damage, dysfunction and failure of different organs, especially the eyes, kidneys, nerves, heart and blood vessels. ${ }^{1}$ Diabetes is classified on the basis of the pathogenic process that leads to hyperglycemia, as opposed to earlier criteria such as age of onset or type of therapy. The two broad categories of diabetes mellitus are designated as type 1 and type 2 . Type 1 diabetes mellitus results from autoimmune beta cell destruction, which leads to insulin deficiency. Type 2 diabetes mellitus is a heterogeneous group of disorders characterized by variable degrees of insulin resistance, impaired insulin secretion and increased glucose production. Although type 1 diabetes mellitus most commonly develops before the age of 30, autoimmune beta cell destruction can develop at any age. Type 2 diabetes mellitus develops more rapidly with increasing age, but it also occurs in children, particularly in obese individuals. $^{2}$ The global prevalence of diabetes is estimated to increase from $4 \%$ in 1995 to $5.4 \%$ by the year 2025 and the number of people with DM are set to rise from an estimate of 150 million in 2008 to 220 million in 2010 and 300 million in 2025. ${ }^{3,4}$ The countries with the largest number of diabetic people are and will be in the year 2025, India, China and United States. ${ }^{3}$ The International Diabetes Federation (IDF) estimates the total number of diabetic subjects to be around 40.9 million in India and this is further set to rise to 69.9 million by the year $2025 .^{5}$ Despite the availability of insulin and many oral hypoglycemic drugs diabetes mellitus still remains a major health concern for humans. 
Therefore new therapeutic approaches are needed to treat diabetes more efficiently. There is a growing interest in focusing on the beneficial role of "alternative therapeutics" in the treatment of diabetes. ${ }^{6}$

Oxalis corniculata Linn. (family-Oxalidaceae) also known as creeping wood sorrel grows at subtropical climate, being native to India and especially abundant in the north-east. It is a herbaceous plant distributed in damp shady places, roadside, lawns. Phytochemical investigations of the plant have revealed presence of flavonoids, Vitamin-C, carotene, oxalates etc. It is used as an antihelminthic, anti-inflammatory, analgesic, astringent, diuretic and stomachic. Some studies have shown the plant to have wound healing, cardio relaxant, anticancer, antimicrobial, antifungal, anti implantation and abortifacient activity. ${ }^{7-12}$

The present study aims to evaluate the antidiabetic effect of different doses of ethanolic extract of Oxalis corniculata in streptozotocin induced diabetic rats. The significance of their antidiabetic effect is compared with standard drug, glibenclamide.

\section{METHODS}

\section{Ethical review}

The protocol was submitted to the Institutional Animal Ethics Committee of Gauhati Medical College and Hospital, Guwahati, India bearing CPCSEA Registration No. 351, 3/1/2001. It was approved by the Committee bearing approval no. MC/32/2013/3 and the CPCSEA guidelines were adhered to during the study.

\section{Drugs and chemicals used in the study}

Ethanolic extract of Oxalis corniculata (EEOC), glibenclamide (obtained from Sigma Aldrich India, Bangalore), streptozotocin (obtained from Himedia, Mumbai), normal saline $(0.9 \% \mathrm{NaCl})$, gum acacia.

\section{Plant material}

Whole plant of Oxalis corniculata Linn. was collected from in and around Guwahati, India. Authentication of the plant was done in the Department of Botany, Gauhati University and a voucher specimen was preserved for further reference. The whole plant was thoroughly washed, shade dried and then chopped to a coarse powder using a mixer grinder. Powder (200 g) was tightly packed in Soxhlet apparatus and extracted employing ethanol as solvent for 5 days at a temperature of $40-60^{\circ} \mathrm{C}$ using a heating mantle. The extract was filtered using Whatman filter paper no.1 and the filtrate was evaporated on a water bath until it gets concentrated. The jelly-like extract of the leaves was collected in a petri dish. A final yield of $40.5 \mathrm{~g}$ was obtained. The percentage yield of Oxalis corniculata was $20.25 \%(\mathrm{w} / \mathrm{w})$ with respect to the original dried powder. The extract was stored in a refrigerator at $4^{\circ} \mathrm{C}$ in labelled air-tight containers for further use.

\section{Experimental animals used in the study}

The study was carried out in healthy albino rats of Sprague Dawley variety of either sex weighing between 200-250 gm. procured from animal house, Gauhati Medical College. The animals were fed on rat chaws diet and water ad libitum during the experiment. Animals were maintained under controlled condition with 12 hour light and 12 hour dark cycles at a temperature of $24 \pm 1{ }^{\circ} \mathrm{C}$ and humidity of $55 \pm 5 \%$. Before conducting the experiment all the animals were acclimatized to laboratory condition for 7 days. The animals were housed in separate polypropylene cages inside a well ventilated room and their bedding changed from time to time.

\section{Acute toxicity study}

Acute toxicity study was done according to OECD 425 guidelines. The animals were found to be alive at 2000 $\mathrm{mg} / \mathrm{kg}$ per oral feeding of the ethanolic extract of Oxalis corniculata (EEOC).

\section{Induction of diabetes in rats}

The animals were fasted overnight prior to the induction of diabetes. Streptozotocin (Product code 1758) of Himedia Laboratories, India was dissolved in ice cold 0.1 $\mathrm{M}$ citrate buffer, $\mathrm{pH} 4.5$ and always prepared freshly for immediate use within 5 min. $^{13}$

STZ injections were given i.p. in a single dose of 50 $\mathrm{mg} / \mathrm{kg}$ body wt. and the doses were determined according to the body weight of animals. In the present study the blood glucose levels were evaluated on day 0 in all the rats prior to administration of streptozotocin. On day 3 i.e. after 72 hours, the blood glucose levels were evaluated and the rats with blood glucose level $>250$ $\mathrm{mg} / \mathrm{dl}$ were considered as diabetic and taken up for the study. Pascoe et al in 1990 mentioned that in general, rats are considered diabetic if tail blood glucose concentrations are greater than 200-300 mg/dl, 2 days after STZ injection. ${ }^{14}$

\section{Collection of blood sample and blood glucose determination}

Blood samples were drawn from tail tip of rat during the study. Fasting blood glucose estimation was done on day $0,3,7,14$ and 21 of the study. For the estimation of blood glucose level Accu-Chek Active glucometer (A product of Roche Diagnostics, Germany) was used where the blood glucose level were expressed in $\mathrm{mg} / \mathrm{dl}$. This method has adequate sensitivity with the advantage that a small amount of blood (1-2 $\mu \mathrm{L})$ can be used for blood glucose analysis. Blood sample was collected by cutting the tail tips with a sharp blade and put on the glucose test strip on the glucometer. ${ }^{15}$ After collection of blood, the 
tail tips were exposed to povidone iodine ointment to counteract the possibility of infection and inflammation.

\section{Experimental design}

The albino rats were divided into 5 groups, each consisting of 6 animals. Diabetes was induced by a single i.p. injection of streptozotocin at a dose of $50 \mathrm{mg} / \mathrm{kg}$ body weight. Except Group I all the other 4 groups were induced with diabetes. From 4th day onwards standard drug, glibenclamide and ethanolic extract of Oxalis corniculata was fed to the rats and it was continued till the end of the study.

The animals included in the experiment were divided as follows:

- Group I: Normal control group: Received normal saline in the dose of $10 \mathrm{ml} / \mathrm{kg} /$ day per orally.

- Group II: Diabetic control group: Received normal saline in the dose of $10 \mathrm{ml} / \mathrm{kg} /$ day per orally.
- Group III: Diabetic standard group: Received glibenclamide at a dose of $0.5 \mathrm{mg} / \mathrm{kg} /$ day per orally.

- Group IV: Diabetic test: Received ethanolic extract of Oxalis corniculata $200 \mathrm{mg} / \mathrm{kg} /$ day per orally.

- Group V: Diabetic test: Received ethanolic extract of Oxalis corniculata $400 \mathrm{mg} / \mathrm{kg} /$ day per orally.

\section{Statistical analysis}

The statistical analysis was carried out using graph pad prism 5.01 software. Data were expressed as mean \pm SEM. Results were analyzed by one way analysis of variance (ANOVA), followed by Dunnett's multiple comparison test. $\mathrm{p}$ value $<0.05$ was considered as statistically significant.

\section{RESULTS}

On day 0 i.e. the day when streptozotocin was injected, prior to its administration the blood glucose levels were evaluated in all the rats.

Table 1: Effect of ethanolic extract of Oxalis corniculata Linn on blood glucose level in streptozotocin induced diabetic rats (mean blood glucose level \pm SEM In mg/dl).

\begin{tabular}{|c|c|c|c|c|c|c|}
\hline \multicolumn{2}{|c|}{ Groups } & Day 0 & Day 3 & Day 7 & Day 14 & Day 21 \\
\hline \multicolumn{2}{|c|}{ Group I (Normal control) } & $106.33 \pm 2.290$ & $108.66 \pm 3.084$ & $109.16 \pm 2.315$ & $113.33 \pm 1.085$ & $113.50 \pm 1.607$ \\
\hline \multicolumn{2}{|c|}{ Group II (Diabetic control) } & $115.00 \pm 2.633$ & $457.50 \pm 2.837^{\mathrm{a}}$ & $461.33 \pm 2.108^{\mathrm{a}}$ & $466.66 \pm 2.108^{\mathrm{a}}$ & $472.00 \pm 2.113^{\mathrm{a}}$ \\
\hline \multicolumn{2}{|c|}{$\begin{array}{l}\text { Group III (Diabetic } \\
\text { standard) }\end{array}$} & $109.16 \pm 2.574$ & $449.83 \pm 1.904^{\mathrm{a}}$ & $310.66 \pm 1.706^{\mathrm{b}}$ & $193.33 \pm 2.512^{b}$ & $117.16 \pm 8.288^{b}$ \\
\hline \multicolumn{2}{|c|}{$\begin{array}{l}\text { Group IV Diabetic test } \\
\text { (EEOC } 200 \mathrm{mg} / \mathrm{kg})\end{array}$} & $108.33 \pm 2.968$ & $455.50 \pm 2.125^{\mathrm{a}}$ & $359.50 \pm 3.757^{\mathrm{b}}$ & $304.83 \pm 5.166^{\mathrm{b}}$ & $235.66 \pm 1.909^{b}$ \\
\hline \multicolumn{2}{|c|}{$\begin{array}{l}\text { Group V Diabetic test } \\
(\text { EEOC } 400 \mathrm{mg} / \mathrm{kg})\end{array}$} & $114.83 \pm 2.763$ & $455.33 \pm 2.245^{\mathrm{a}}$ & $331.83 \pm 1.744^{\mathrm{b}}$ & $238.33 \pm 1.429^{b}$ & $167.66 \pm 5.475^{\mathrm{b}}$ \\
\hline \multirow{3}{*}{ ANOVA } & $\mathrm{F}$ & 2.219 & 3892 & 2764 & 2185 & 1010 \\
\hline & df & 4,25 & 4,25 & 4,25 & 4,25 & 4,25 \\
\hline & $\mathrm{p}$ & $>0.05$ & $<0.01$ & $<0.01$ & $<0.01$ & $<0.01$ \\
\hline
\end{tabular}

Values are expressed as Mean \pm SEM $(n=6)$. One Way ANOVA followed by Dunnett's multiple comparison tests is done. ${ }^{\text {a }} \mathrm{p}<0.01$ when compared to the Normal control group. ${ }^{b} \mathrm{p}<0.01$ when compared to the Diabetic control group.

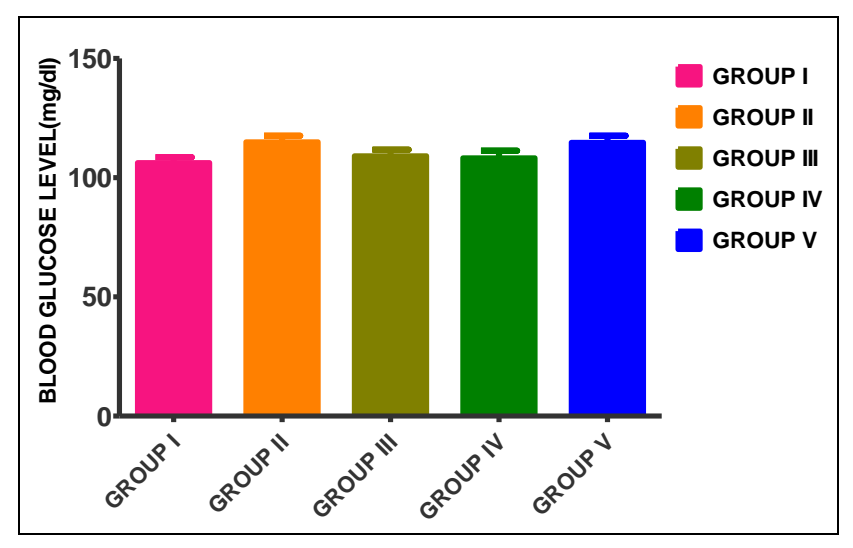

Figure 1: Blood glucose levels on day 0 .

In the normal control group the mean blood glucose levels was found to be $106.33 \pm 2.290$, in the diabetic control group it was found to be $115.00 \pm 2.633$, in the diabetic standard group it was found to be $109.16 \pm 2.574$,in the diabetic test (EEOC $200 \mathrm{mg} / \mathrm{kg}$ ) it was found to be $108.33 \pm 2.968$ and in the diabetic test (EEOC $400 \mathrm{mg} / \mathrm{kg}$ ) it was $114.83 \pm 2.763$.On day 0 the $\mathrm{p}$ value which was $0.0958(>0.05)$ was found to be insignificant as far as the mean blood glucose levels were concerned (Figure 1).

On day 3, the blood glucose levels were estimated in the rats. In the normal control group the mean blood glucose levels was found to be $108.66 \pm 3.084$. In the diabetic control group it was found to be $457.50 \pm 2.837$, in the diabetic standard group it was $449.83 \pm 1.904$, in the diabetic test (EEOC $200 \mathrm{mg} / \mathrm{kg}$ ) the blood glucose level was $455.50 \pm 2.125$ and in the diabetic test (EEOC $400 \mathrm{mg} / \mathrm{kg}$ ) the blood glucose level was $455.33 \pm 2.245$. The rise in blood glucose level was due to the effect of 
streptozotocin on the rats. One way ANOVA of the data followed by Dunnett's test was done with normal control and diabetic control as the control column. There was significant difference $(\mathrm{p}<0.05)$ in mean blood glucose level when group I (normal control) was taken as the control column with all the other 4 groups. But when Group II (diabetic control) was taken as the control column there was significant difference with group I only and not the other groups (Figure 2).

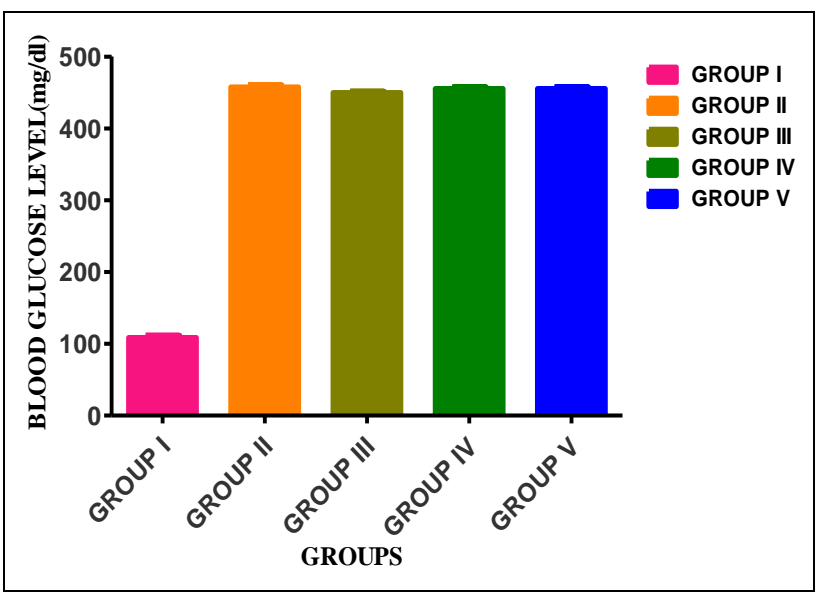

Figure 2: Blood glucose levels on day 3.

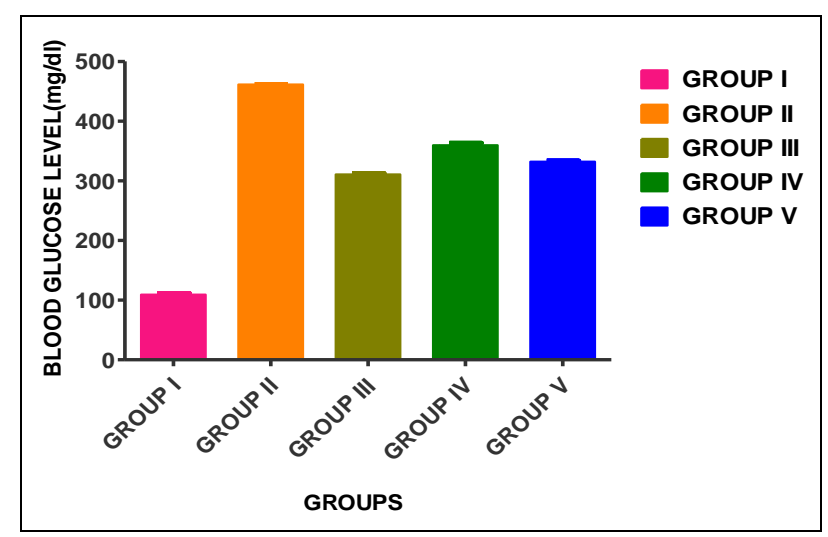

Figure 3: Effects on blood glucose levels on day 7.

On day 7, the blood glucose levels were observed to look for the change that had taken place due to administration of the test drugs from day 4 to day 6 . In the normal control group the mean blood glucose levels was found to be $109.16 \pm 2.315$. In the diabetic control group it was found to be $461.33 \pm 2.108$. As there was no intervention in this group the blood glucose levels were high as before. In the diabetic standard group the blood glucose was $310.66 \pm 1.706$.There was a significant decrease in this group as it was treated with glibenclamide, in the diabetic test (EEOC $200 \mathrm{mg} / \mathrm{kg}$ ) the blood glucose level was $359.50 \pm 3.757$ and in the diabetic test (EEOC $400 \mathrm{mg} / \mathrm{kg}$ ) the blood glucose level was $331.83 \pm 1.744$. One way ANOVA of the data followed by Dunnett's test was done. There was significant difference in between the groups in the blood glucose level on day 7 .

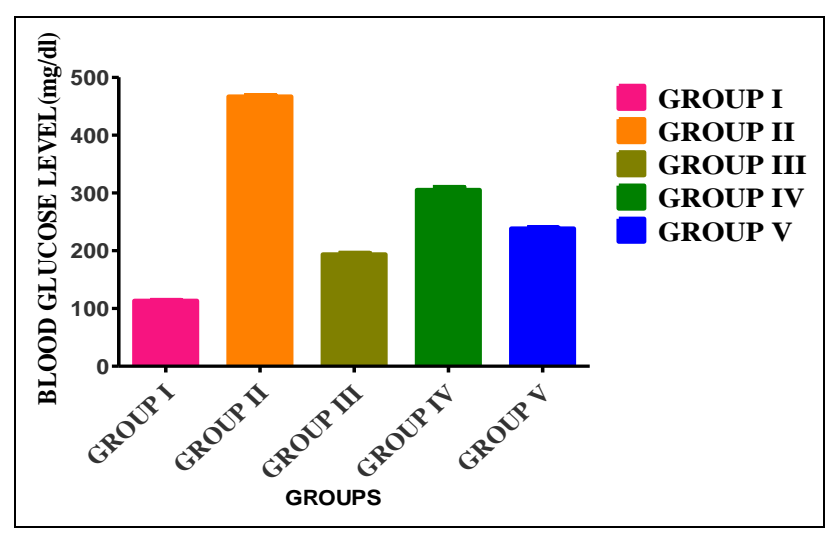

Figure 4: Effect on blood glucose levels on day 14.

On day 14, the blood glucose levels were observed again to determine if any change had taken due to feeding the rats with the standard drug and extract doses over the past 7 days. In the normal control group the mean blood glucose level was found to be $113.33 \pm 1.085$. In the diabetic control group it was found to be $466.66 \pm 2.108$. As there was no intervention in this group the blood glucose levels were high as before. In the diabetic standard group the blood glucose was $193.33 \pm 2.512$, in the diabetic test (EEOC $200 \mathrm{mg} / \mathrm{kg}$ ) the blood glucose level was $304.83 \pm 5.166$ and in the diabetic test (EEOC $400 \mathrm{mg} / \mathrm{kg}$ ) the blood glucose level was $238.33 \pm 1.429$. One way ANOVA of the data followed by Dunnett's test was done. There was significant difference in between the groups in the blood glucose level on day 14 (Figure 4).

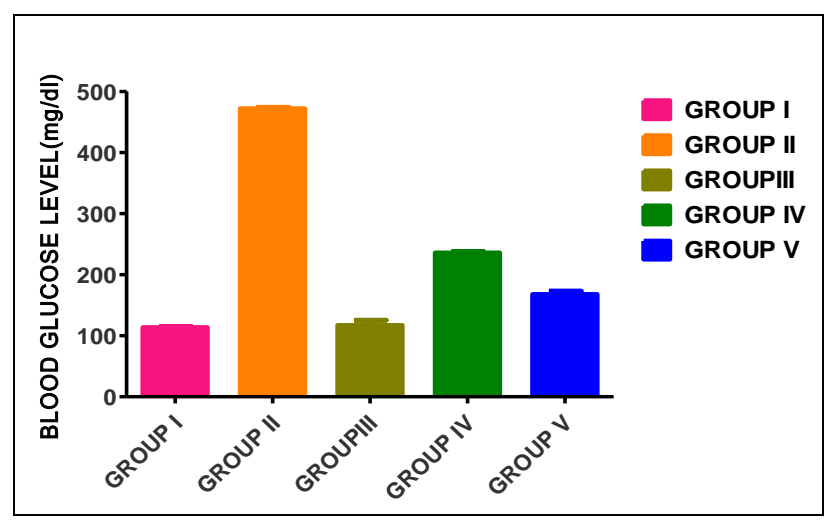

Figure 5: Effect on blood glucose level on day 21.

On day 21, the blood glucose levels were observed again to determine the trend due to feeding the rats with the standard drug and extract doses over the past 7 days. In the normal control group the mean blood glucose levels was found to be $113.50 \pm 1.607$. In the diabetic control group it was found to be $472.00 \pm 2.113$. In the diabetic standard group the blood glucose was $117.16 \pm 8.288$, in the diabetic test (EEOC $200 \mathrm{mg} / \mathrm{kg}$ ) the blood glucose level was $235.66 \pm 1.909$ and in the diabetic test (EEOC $400 \mathrm{mg} / \mathrm{kg}$ ) the blood glucose level was $167.66 \pm 5.475$. One way ANOVA of the data followed by Dunnett's test 
was done. There was significant difference in between the groups in the blood glucose level on day 21 except normal control and diabetic standard group as the blood glucose level in that group had returned to normal level (Figure 5).

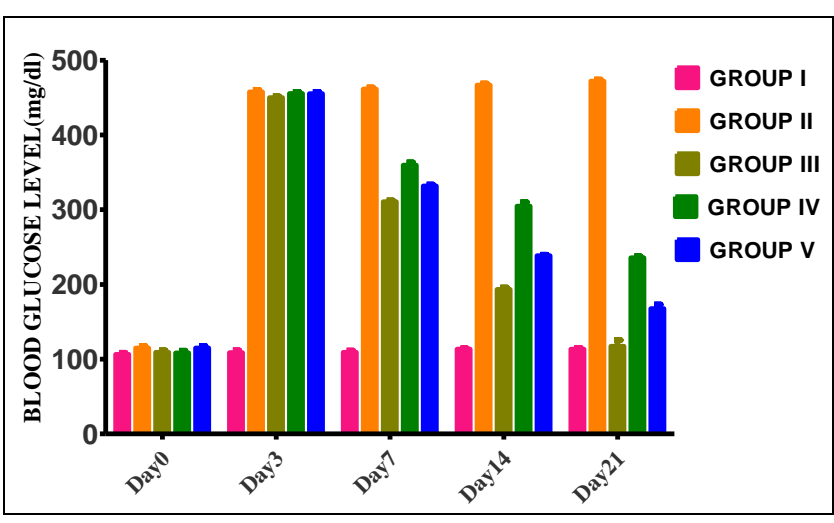

Figure 6: Overall effects on blood glucose level in various groups during the study.

It is a pointer to the fact that the antidiabetic property of the extract has shown increasing trend with increase in dose and there was a gradual decrease in blood glucose levels with increased period of exposure to the test drug (Figure 6).

\section{DISCUSSION}

Due to the nature and complexity of diabetes and the lack of an effective cure, traditional herbal medicine or alternative medicine as it is known in the scientific world today has been explored for potential ways to control, manage and cure diabetes. ${ }^{16}$ Medicinal plants are a rich source of natural products and these have been used for the treatment of diabetes all around the world with less known scientific basis of their function. ${ }^{17}$

The STZ induced diabetic rat is one of the animal models of human diabetes mellitus. Diabetes arises from irreversible destruction of pancreatic $\beta$ cells, causing reduction of insulin secretion.

The observed increased blood glucose level in the study is in agreement with reports by several workers that STZ induced diabetes mellitus leads to increased blood glucose. It has been reported that STZ at lower doses produce partial destruction of pancreatic $\beta$ cells with permanent diabetes condition and there is possibility of many surviving $\beta$ cells. Since a low dose of STZ ( $50 \mathrm{mg} / \mathrm{kg}$ body wt. i.p.) was chosen for this study there might have been many surviving $\beta$ cells, capable of undergoing regeneration. ${ }^{18}$

Glibenclamide, a standard hypoglycemic agent was taken for comparison of the glucose lowering effectiveness of the ethanolic extract of Oxalis corniculata. For the estimation of blood glucose level Accu-Chek active glucometer (A product of Roche Diagnostics, Germany) was used. This method has adequate sensitivity with the advantage that a small amount of blood (1-2 $\mu \mathrm{L})$ can be used for blood glucose analysis.

Albino rats have been used for experimental models of hyperglycemia. They are the commonest laboratory animals suitable for experimental work because of their small size, greater sensitivity to most drugs, easy breeding and resemblance to human nutritionally. ${ }^{19}$

The study shows that the ethanolic extract of Oxalis corniculata has antidiabetic potential even though it is lesser than the standard drug, glibenclamide. The results on the antidiabetic potential of Oxalis corniculata run parallel with the study carried out by Agila $\mathrm{KN}$ et al to look for the antidiabetic effect of the plant in alloxan induced diabetic mice. ${ }^{20}$

In the present study, glibenclamide, a member of sulphonylurea is used as the standard drug. It has been proposed that sulphonylurea produce their hypoglycemic effect primarily through increased release of insulin in pancreatic $\beta$ cells. Thus any plant secondary metabolite or chemical constituent which is capable of affecting the insulin secretion from pancreatic $\beta$ cells will be a good mimicker of sulphonylureas. ${ }^{21}$ The ethanolic extract of Oxalis corniculata was able to significantly lower the blood glucose level. Therefore, the extract might have been able to potentiate the release of insulin from pancreatic islets similar to that of results observed after glibenclamide administration. Also there is a possibility that there might be the presence of some constituents with insulin like action which directly lowered the blood glucose level independent of insulin secretion.

Srikanth et al in their review on Oxalis corniculata reveals that wide range of phytochemical constituents have been isolated from the plant like alkaloids, flavonoids, tannins, phytosterols, phenol, glycosides, fatty acids, galacto-glycerolipid and volatile oil. ${ }^{22}$ Plants which contain active principles like glycosides, alkaloids, terpenoids, flavonoids have antioxidant property and are claimed to possess antidiabetic activity. ${ }^{23}$ Antioxidant action has beneficial effects on preservation of $\beta$ cell function in diabetes. ${ }^{24}$ The insulin releasing action or insulin like action of the extract may be due to the presence of flavonoids that might have triggered the $\mathrm{Ca}^{2+}$ mediated mechanisms for insulin release or might have modulated the voltage dependent channel inactivation mechanism by altering voltage sensitivity. ${ }^{25}$ However the exact cellular and molecular mechanisms underlying the antidiabetic action of Oxalis corniculata still remains unclear and there is scope for further research on the subject.

\author{
Funding: No funding sources \\ Conflict of interest: None declared \\ Ethical approval: The study was approved by the \\ Institutional Ethics Committee
}




\section{REFERENCES}

1. American Diabetes Association. Position Statement: Diagnosis and Classification of Diabetes Mellitus. Diabetes care.2010;33(1):562-69.

2. Powers AC. Diabetes mellitus. Kasper DL, Braunwald E., Fauci AS, Hauser SL, Longo DL, Jameson JL. Harrison's Principles of Internal Medicine. NewYork: Mc Graw Hill. 2012;18(2):2968-3003.

3. Ramachandran A, Snehalatha C, Viswanathan V. Burden of type 2 diabetes and its complications- the Indian scenario. Current Sci. 2002;83(12):1471-6.

4. Thevenod F. Pathophysiology of diabetes mellitus type 2: roles of obesity, insulin resistance and $\beta$-cell dysfunction. diabetes and cancer epidemiological evidence and molecular links. front diabetes. Basel, Karger. 2008;19:1-18.

5. Mohan V, Sandeep S, Deepa R, Shah B, Varghese B. Epidemiology of type 2 diabetes: Indian scenario. Indian J Med Res. 2007;125:217-30.

6. Porter DJ, Raymond LW, Anastasio GD. Chromium, Friend or foe. Archives of Family Medicine.1999;8(5):386-90.

7. Taranalli AD, Tipare SV, Torgal SS, Kumar S. Wound healing activity of Oxalis corniculata whole plant extract in rats. Indian $\mathbf{J}$ Pharmacology. 2004;66:444-46.

8. Achola KJ, Mwangi JW, Munenge RW. Pharmacological activity of Oxalis corniculata. Pharmaceutical Biology. 1995;33:247-49.

9. Kathiriya A, Das K, Kumar EP, Mathai KB. Evaluation of antitumor and antioxidant activity of Oxalis corniculata linn. Against Ehrlich ascites carcinoma on mice, Iranian Journal of Cancer Prevention. 2010;4:157-65.

10. Raghvendra MP, Satish S. Raveesha KA. Phytochemical analysis and antibacterial activity of Oxalis corniculata, a known medicinal plant. Science. 2006;1:72-8.

11. Verma RK, Chaurasia L, Katiyar S. Potential antifungal plants for controlling building fungi. Natural Product Radiance. 2008;7(4):374-87.

12. Sharangouda K, Patil SB. Antiimplantation and abortifacient activities of Oxalis corniculata in albino rats. Nigerian Journal of Natural Products and Medicine. 2007;11:58-60.

13. Babu PS, Mainzen S, Prince P. Antihyperglycaemic and antioxidant effect of hyponidd, an ayurvedic herbomineral formulation in streptozotocin induced diabetic rats. J. Pharm Pharmacol. 2004;56(11):1435-42.
14. Pascoe WS, Storlien LH. Inducement by feeding of basal hyperglycemia in rats with abnormal $\beta$-cell function. Diabetes. 1990;39:226-33.

15. Ilham S, Ali MS, Hasan CM, Kaisar MA, Bachar SC. Antinociceptive and hypoglycemic activity of methanolic extract of Phlogacanthus thyrsiflorus. Asian Journal of Pharmaceutical and Clinical Research. 2012;5(2):15-8.

16. Chau $\mathrm{CF}, \mathrm{Wu} \mathrm{SH}$. The development of regulations of Chinese herbal medicines for both medicinal and food uses. Trends in Food Sciences and Technology. 2006;17:313-23.

17. Patwardhan B, Vaidya ADB, Chorghade M. Ayurveda and natural products drug discovery. Current Science. 2004;86:789-99.

18. Mahalingam G, Krishnan K. Antidiabetic and ameliorative potential of Ficus bengalensis bark extract in streptozotocin induced diabetic rats. Indian Journal of Clinical Biochemistry. 2008;23(4):394400.

19. Ghosh MN. Chapter1.Common laboratory animals. Fundamentals of experimental pharmacology. Kolkata: Hilton and Company. 2008;1-14.

20. Agila KN, Kavitha R. Antidiabetic, antihyperlipidaemic and antioxidant activity of Oxalis corniculata in alloxan induced diabetic mice. Journal of Natural Sciences Research. 2012;2(7):917.

21. Prato DS, Pulizzi N. The place of sulphonylureas in the therapy for type 2 diabetes mellitus. Metabolism. 2006;55:20-7.

22. Srikanth M, Tadigotla S, Veeresh B. Phytochemistry and pharmacology of Oxalis corniculata linn: a review. International Journal of Pharmaceutical Sciences and Research. 2012;3(11):4077-85.

23. Soud ENA, Khalil MY, Hussain JS, Oraby FH, Farrag AH. Antidiabetic effects of fenugreek alkaloid extract in streptozotocin induced hyperglycaemic rats. Journal of Applied Sciences Research. 2007;3(10):1073-83.

24. Kaneto H, Kajimoto Y, Miyagawa J, Matsuoka T, Fujitani Y, Umayahara Y et al. Beneficial effects of antioxidants in diabetes: possible protection of pancreatic $\beta$ cells against glucose toxicity. Diabetes. 1999;48:2398-406.

25. Sachan NK, Kumar Y, Pushkar S, Thakur RN, Gangwar SS, Kalaichelvan VK. Antidiabetic potential of alcoholic and aqueous extracts of Ficus Racemosa Linn. bark in normal and alloxan induced diabetic rats. International Journal of Pharmaceutical Sciences and Drug Research. 2009;1(1):24-7.

Cite this article as: Dutta A, Lahkar M, Handique C. Evaluation of antidiabetic activity of Oxalis corniculata in streptozotocin induced diabetic rats. Int J Basic Clin Pharmacol 2016;5:2178-83. 